medRxiv preprint doi: https://doi.org/10.1101/2020.04.30.20086751; this version posted May 5, 2020. The copyright holder for this preprint (which was not certified by peer review) is the author/funder, who has granted medRxiv a license to display the preprint in perpetuity.

It is made available under a CC-BY-ND 4.0 International license .

1 Title: Prediction of the Epidemic Peak of Covid19 in Egypt, 2020

2 Author: Eman D.El Desouky

3 Epidemiology and Biostatistics, National Cancer Institute, Cairo University,

4 eman.desouky@nci.cu.edu.eg

5

6 Address: Kasr Al Eini ‘Street ‘Fom El Khalig ‘Cairo Governorate,

7 Postal code: 11796 


\section{Prediction of the Epidemic Peak of Covid19 in Egypt, 2020}

\section{Abstract}

3 Objectives: Since December 2019 a pandemic of new novel coronavirus has started from

4 Wuhan, China, in Egypt, the first case reported on February 14, 2020. In this study we

5 aimed to predict the time of possible peak and simulate the changes could be happen by

6 the social behavior of Egyptians during Ramadan (the holy month).

8 Methods: SIR and SEIR compartmental models were used to predict the peak time. We

9 simulated different expected scenarios based to examine their effects on the peak timing.

10 Results: We found that the peak most likely to be in middle of June 2020. Simulating

11 different transmission rate probability and R0 the earliest peak could to be in the May 20

12 and latest one could be in 18 July. The peak shifted much earlier to $11^{\text {th }}$ April 2020

13 without lockdown and other mitigation strategies.

14 Conclusion: Social behaviors of citizens during the holy month will dramatically affect

15 the peak timing. Mitigations strategies and other lockdown measure helped to delay the 16 expected peak.

17 Keywords: COVID-19; compartmental models; Epidemic peak; Egypt 
medRxiv preprint doi: https://doi.org/10.1101/2020.04.30.20086751; this version posted May 5, 2020. The copyright holder for this preprint (which was not certified by peer review) is the author/funder, who has granted medRxiv a license to display the preprint in perpetuity.

It is made available under a CC-BY-ND 4.0 International license.

\section{Introduction}

2 The first case of respiratory disease caused by a novel coronavirus was identified in

3 Wuhan City, Hubei Province, China in In December 2019 and on 13 January 2020 the

4 first case outside of China was reported in Thailand. ${ }^{1}$ On $11^{\text {th }}$ March 2020 the World

5 Health Organization named it coronavirus disease 2019 (COVID-19) and considered as

6 pandemic. $^{2}$ The first case appeared in Egypt on $14^{\text {th }}$ February 2020 for a foreigner and

7 fortunately was asymptomatic until $1^{\text {st }}$ of March 2020 he was the only reported case after

8 that few cases started to appear till $14^{\text {th }}$ March 2020 to reach 110 cumulatively, and then

9 the number of laboratory confirmed cases increased weekly (Table 1) to reach 3490 till

10 April 22, 2020. ${ }^{3}$

11 Table 1. Number of cumulative COVID-19 cases in Egypt until $23^{\text {th }}$ April 2020

\begin{tabular}{lc}
\hline$\ldots$ & No of Cumulative cases \\
\hline 14 February -20 February & 1 \\
21 February -27 February & 1 \\
28 February -5 March & 1 \\
6 March -12 March & 3 \\
13 March -19 March & 80 \\
20 March -26 March & 256 \\
27 March -2 April & 495 \\
3 April - 9 April & 865 \\
10 April-16 April & 1699 \\
17 April-22 April & 3490 \\
\hline
\end{tabular}

12

13

14

15

16

17

18

19

20

21

22

23

24

As seen in table 1 the numbers started nearly to double weekly from the fifth week and after closure of schools with partial lockdown the public concerned about the timing of the cases surge. The aim of this study is to predict the time of possible peak and simulate the changes that might happen by the social behavior of Egyptians during Ramadan (the holy month) that will begins on Friday April 24 and ends on Saturday May 23. In Ramadan families usually gather especially in first days, children have more activates with each other's and everyone leaves work at the same time and need to be in home at the same time ; currently with Covid19 pandemic and partial lock down it's challenging to cope with social distancing and Ramadan habits . 


\section{Methods:}

2 We tested two models SIR and SEIR models ${ }^{4}$ to predict peak timing using data till 17 th

3 April 2020 and simulated different scenarios based on hypothetical expected changes in

$4 \quad$ social behavior of Egyptians during Ramadan .

5 1- SIR model

6

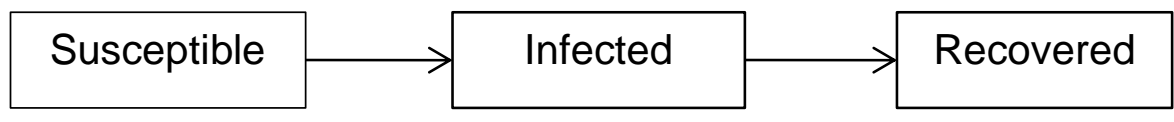

$$
\left\{\begin{array}{c}
\mathrm{S}^{\prime}(\mathrm{t})=-\beta \mathrm{S}(\mathrm{t}) \mathrm{I}(\mathrm{t}), \\
\mathrm{I}^{\prime}(\mathrm{t})=\beta \mathrm{S}(\mathrm{t}) \mathrm{I}(\mathrm{t})-\gamma \mathrm{I}(\mathrm{t}), \\
\mathrm{R}^{\prime}(\mathrm{t})=\gamma \mathrm{I}(\mathrm{t}), \\
\mathrm{t}>0
\end{array}\right\}
$$

\section{2- SEIR model}

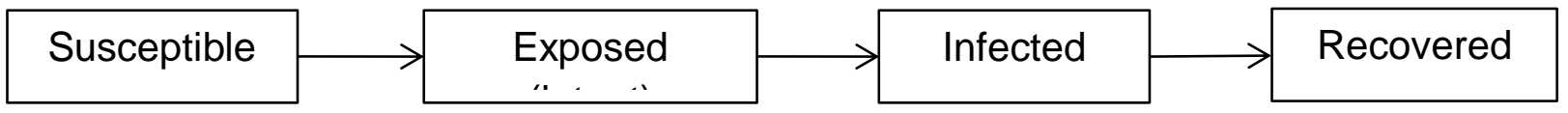

$$
\left\{\begin{array}{cl}
\mathrm{S}^{\prime}(\mathrm{t})=-\beta \mathrm{S}(\mathrm{t}) \mathrm{I}(\mathrm{t}), & \mathrm{E}^{\prime}(\mathrm{t})=\beta \mathrm{S}(\mathrm{t}) \mathrm{I}(\mathrm{t})-\varepsilon \mathrm{E}(\mathrm{t}), \\
\mathrm{I}^{\prime}(\mathrm{t})=\varepsilon \mathrm{E}(\mathrm{t})-\gamma \mathrm{I}(\mathrm{t}), & \mathrm{R}^{\prime}(\mathrm{t})=\gamma \mathrm{I}(\mathrm{t}), \quad \mathrm{t}>0,
\end{array}\right\}
$$

Where $S(t), E(t), I(t)$ and $R(t)$ represent the susceptible, exposed, infective and removed populations at time $\mathrm{t}$, respectively. $\beta, \varepsilon$ and $\gamma$ represent the infection rate, the onset rate

17 and the removal rate, respectively. $1 / \varepsilon$ and $1 / \gamma$ imply the average incubation period and

18 the average infectious period, respectively. The force of infection (rate of infection per

19 unit time is $\beta I$ and $\beta$ denoted the rate of transmission from $\mathrm{S}$ to I or effective contact

20 between $\mathrm{S}$ and $\mathrm{I}^{5}$

21 These models based on Euler`s Method: A numerical method for solving differential

22 equations and referred to as a compartment model since it is useful to refer to people

23 moving from one compartment to another.

24 Parameters used in the models based on previous studies assuming average Incubation

25 period $=5$ days and so onset rate $\varepsilon=0.2^{6}$, assuming infectious period $=10$ day and so

26 removal rate $\gamma=0.1{ }^{7}$ Egypt population $\left(1 \times 10^{8}\right)^{8}$, no one infected at the time $\left(\mathrm{t}_{0}\right)$ time step

27 is one day and population remain constant so $\mathrm{S} \pm \mathrm{E}+\mathrm{I}+\mathrm{R}=1$. 
1 Regarding transmission rate $(\beta)$ and Basic reproduction number $\left(\mathrm{R}_{0}\right)$ researcher depended

2 on the published data available on GitHub , midas-network ${ }^{9}, \mathrm{R}_{0}$ for Egypt as published

32.3 and so $\beta=0.23$ by applying the formula;

$4 \quad R 0=\frac{\beta}{\gamma} 10$

5 For the purpose of simulation different scenario of effective contacts during Ramadan,

6 different $\mathrm{R}_{0}$ and $\beta$ were used within the range of previous published data available on

7 midas-network. $^{9}$

8 Starting from model1 (M1) that represent less effective contact rate than the current

9 situation $\left(\beta=0.22, \mathrm{R}_{0}=2.2\right)$ till model10 (M10) that represent higher effective contact rate

10 with $\beta=0.32$ and $\mathrm{R}_{0}=3.2$

11 The peak was identified by the maximum proportion of population infected in a year

12

\section{$\underline{\text { Results }}$}

Researcher used SIR model with different simulation scenarios to predict peak timing, illustrated in figure1. The earliest of peak could be on May 20, 2020 and latest peak could be July 18, 2020, then applied Applying regression method to estimate the best fitted models with the cumulative data released by MOHP till 17th April, 2020; peak on 15 June 2020 is more likely.

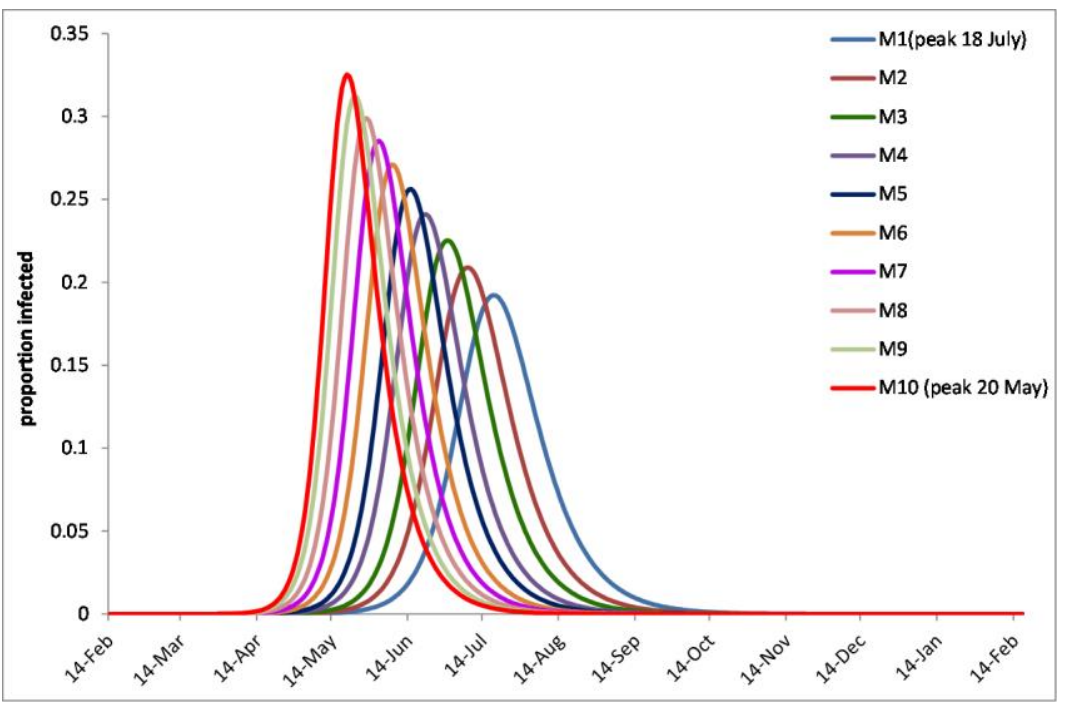

Figure (1): Different models estimating different peaks with SIR model 
1 Researcher used SEIR Peak prediction models almost similar results obtained; earliest

2 peak could be May 17, 2020 and latest peak could be by July 15, 2020.

3

The $3^{\text {rd }}$ scenario was estimating the peak time without lockdown and other strategies based on mobility changes report released by google ${ }^{11}$ that stated average $50 \%$ reduction in Egypt since the time of lockdown and mitigation strategies. The peak was estimated to occur on $11^{\text {th }}$ April 2020 but with mitigation strategies and lockdown it was shifted about

69 days to reach June 15, 2020 (figure 2).

9

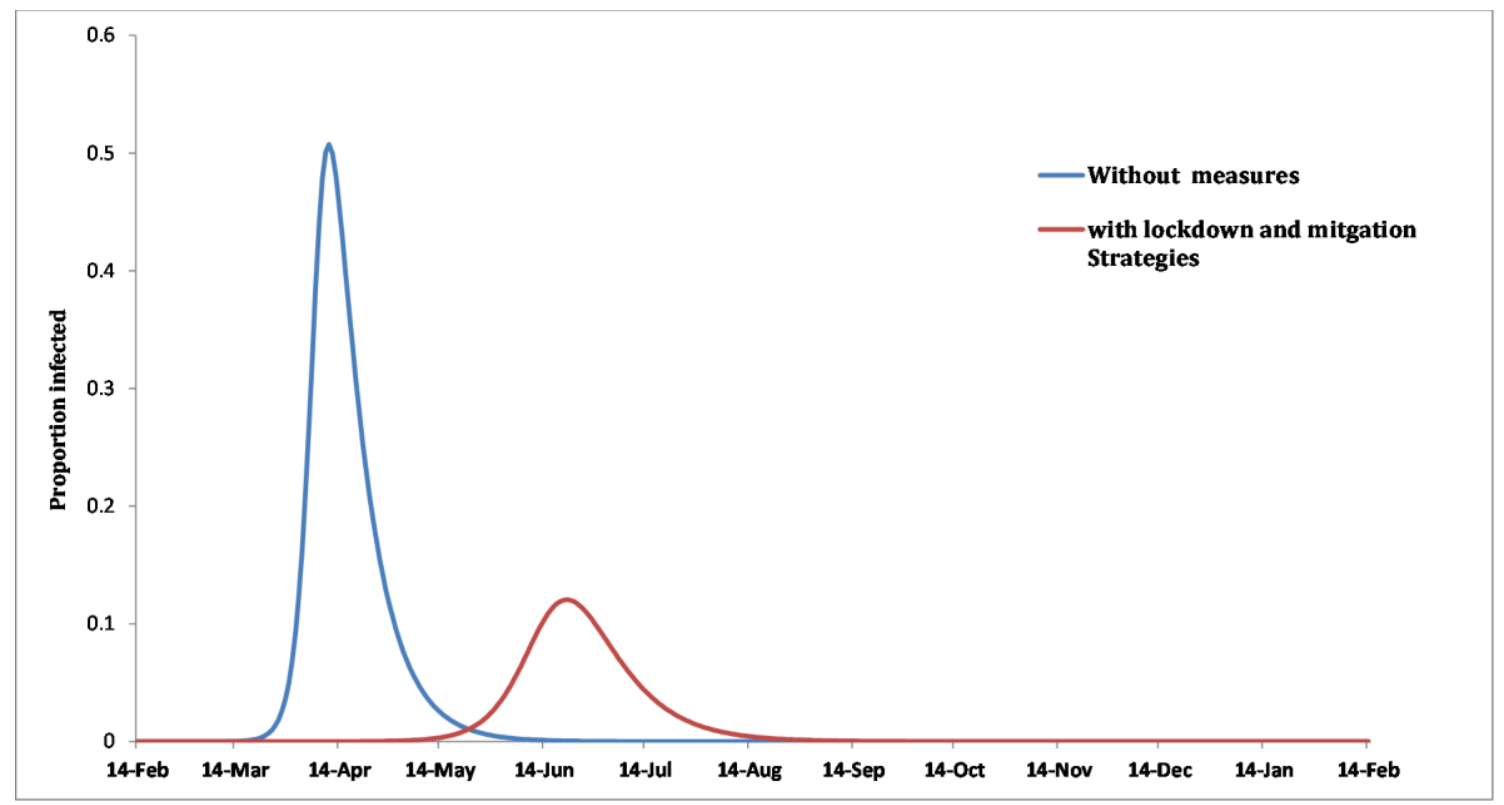

\section{Figure (2): Peak estimation with lockdown and other measures in comparison to the situation without them.}

\section{Discussion}

In this study, by applying the SIR and SEIR compartmental model along with the daily reported cases of Covid19 till $17^{\text {th }}$ April in Egypt; we estimated the peak could be in the middle of June. We hypothesized that the social and contact rate per individual changes in Ramadan (the Holy month) that will start on April 24, 2020 will affect the timing of peak as a result of Increase in $\beta$ (transmission rate). We simulated different situations with different rates of effective contact, transmission rate and $\mathrm{R}_{0}$ consequently; the peak timing changed to reach 20 May, 2020 as earliest one and latest peak could be July 18, 2020. These findings was in concordance with the study done by Pearsn et al ${ }^{12}$ that 
1 reported 10,000 cases could be in 20 May 2020. On the contrast a recent report released

2 by SUTD Data-Driven Innovation Lab ${ }^{13}$ that reported the pandemic will end in Egypt

3 on May 20, 2020. Researcher simulated another scenario based on current data to predict

4 the timing of peak without lockdown the peak shifted earlier to be on April 11, 2020; the

5 mitigation strategies helped to delay peak. The current study simulated different

6 scenarios based on different values on transmission rate (calculated and estimated) in

7 concordance with Bootsma and Ferguson ${ }^{14}$ who stated the most important factor

8 affecting disease pandemic is the transmission rate which depend on crowding as it

9 affects amount of contact per individual. The current study used SIR and SEIR models

10 which are too idealistic for modeling COVID-19 through numerical simulation, but it

11 gives an idea about when the COVID-19 cases can surge to. ${ }^{15}$

12 The study stated long range peak prediction to emphasis the role of social distancing to

13 flatten the curve in concordance with Anderson et al ${ }^{16}$.

14 The result suggests that the epidemic of COVID-19 in Egypt would not end so quickly.

15 This might be reliable with the WHO's statement on 6 March 2020 that it is a false hope

16 that COVID-19 will disappear in the summer like the flu. ${ }^{17}$

\section{Limitations}

18 This is too idealistic for modeling COVID-19 as the reproduction number $\left(\mathrm{R}_{0}\right)$ changes

19 overtime but the multiple simulation may overcome this hypothetically for certain time.

20 The deterministic models are not accurate and used to give insight about what will

21 happen to population on average. Study didn't estimate the hospitalized number at the

22 surge however the timing of the peak didn't affected by the identified cases form the

23 actual infective population.

\section{Conclusions:}

25 During COVID-19 pandemic it's hard to predict the real peak timing however the surge

26 timing will depend mainly on the behavior of citizens towards social distancing and

27 hygiene measures. The mitigation strategies and lockdown in Egypt has a positive effect

28 on the delay of the epidemic peak, giving more time to the health sector to encompass the

29 situation. There is an urgent need for Local and worldwide policy to deal with Covid19

30 that will extend to summer time. Egyptian government should monitor the reported cases

31 daily along with the performance of citizens in the coming month to determine the proper 
1 strategies to flatten the curve as much as possible. The optimistic view to the situation

2 should be treated cautiously as COVID-19 is still unclear.

3

Declaration of interests: The author declares no competing interests.

\section{Reference}

1 CDC, Coronavirus Disease 2019 (COVID-19).

https://www.cdc.gov/coronavirus/2019-ncov/index.html. Accessed 20 Apr 2020

2 WHO, Coronavirus disease 2019.

https://www.who.int/emergencies/diseases/novel-coronavirus-2019. Accessed $20 \mathrm{Apr}$ 2020

3 Egypt cares. 2020. Available from: https://www.care.gov.eg/EgyptCare/Index.aspx Accessed 22 Apr 2020

4 Inaba, H. Age-Structured Populatin Dynamics in Demography and Epidemiology; Springer: Berlin/Heidelberg, Germany, 2017.

5 Abbey H. An examination of the Reed-Frost theory of epidemics. Human biology. 1952 Sep 1;24(3):201.

6 Linton NM, Kobayashi T, Yang Y, Hayashi K, Akhmetzhanov AR, Jung SM, Yuan B, Kinoshita R, Nishiura H. Incubation period and other epidemiological characteristics of 2019 novel coronavirus infections with right truncation: a statistical analysis of publicly available case data. Journal of clinical medicine. 2020 Feb;9(2):538.

7 Sun H, Qiu Y, Yan H, Huang Y, Zhu Y, Chen SX. Tracking and Predicting COVID-19 Epidemic in China Mainland. medRxiv. 2020 Jan 1.

8 CAPMAS. https://www.capmas.gov.eg/Pages/populationClock.aspx. Accessed 22 Apr 2020

9 COVID-19/README.md at master - midas-network/COVID-19. https://github.com/midas-network/COVID 19/blob/master/parameter estimates/2019 novel coronavirus/README.md. Accessed 17 Apr 2020

10 Ridenhour B, Kowalik JM, Shay DK. Unraveling R 0: Considerations for Public Health Applications. American journal of public health. 2018 Dec;108(S6):S445-54. 
medRxiv preprint doi: https://doi.org/10.1101/2020.04.30.20086751; this version posted May 5, 2020. The copyright holder for this preprint (which was not certified by peer review) is the author/funder, who has granted medRxiv a license to display the preprint in perpetuity.

It is made available under a CC-BY-ND 4.0 International license .

111 COVID-19 Community Mobility Report.

2 https://www.gstatic.com/covid19/mobility/2020-04-11 EG Mobility Report en.pdf.

3 Accessed 20 Apr 2020

4

5

612 Pearson CA, Van Schalkwyk C, Foss AM, O'Reilly KM, Pulliam JR,. Projected

7 early spread of COVID-19 in Africa. CMMID COVID-19 working group 2020. 63:25-28

813 SUTD Data-Driven Innovation Lab. "Egypt." Data-Driven Prediction of COVID-

919 Pandemic End Dates, ddi.sutd.edu.sg/portfolio/items/442705. Accessed 23 Apr 2020

1014 Bootsma MC, Ferguson NM. The effect of public health measures on the 1918

11 influenza pandemic in US cities. Proceedings of the National Academy of Sciences. 2007

12 May $1 ; \mathbf{1 0 4}(18): 7588-93$.

13

1415 Wees J Van, Osinga S, Kuip M Van Der, Tanck M, Hanegraaf M, Pluymaekers

15 M, et al. Forecasting hospitalization and ICU rates of the COVID-19 outbreak: an

16 efficient SEIR model. [Submitted]. Bulletin World Health Organaization. E-pub: 30

17 March 2020. doi: http://dx.doi.org/10.2471/BLT.20.256743

18

19

16 Anderson RM, Heesterbeek H, Klinkenberg D, Hollingsworth TD. How will

20 country-based mitigation measures influence the course of the COVID-19 epidemic? The

21 Lancet. 2020 Mar 21;395(10228):931-4.

2217 "False hope" coronavirus will disappear in summer like flu, WHO says. Available

23 from: https://www.cnbc.com/2020/03/06/its-a-false-hope-coronavirus-will-disappear-in-

24 the-summer-like-the-flu-who-says.html. Accessed 18 Apr 2020.

25 